\title{
The Empirical Study of Low Carbon Development and Economic Evaluation System-Take a city in Hebei Province as an Example
}

\author{
Hong Zhang \\ Department of Management Langfang Normal College \\ Langfang, China
}

Keywords: Low-carbon economy; Evaluation System; Analytic hierarchy process.

\begin{abstract}
The low-carbon economy is developed vigorously in the world, but how to evaluate the effect of the low-carbon economy reasonably has not been reached. In this study, analytic hierarchy process (AHP) is used and a city in Hebei Province is taken as an example to establish the low-carbon economy evaluation system so that the weight value of various evaluation indexes are obtained and the emission of $\mathrm{CO}_{2}$ of pr unit GDP has the greatest effects on the low-carbon economy development. Thus, the emission of $\mathrm{CO}_{2}$ should be reduced in many ways and measures in order to improve environment. At the same time, the data between year 2005 and 2011 of the city was used to calculate the comprehensive value of low-carbon economy development level in each year. The comprehensive value between 2006 and 2008 is lower, which is related to socio-economic status at that time. The low-carbon economical development should carry out the policy and making plans strictly, but cannot focus on the current interests. The evaluation system which is objective and reasonable provides the theoretical basis for the city low-carbon economic development.
\end{abstract}

\section{Introduction}

The international social economy develops rapidly at the cost of the consumption of non-renewable energy. With the massive fossil energy consumption, global warming and the frequent occurrence of catastrophic climate ring the alarm bell for the whole mankind. In order to relieve and improve the earth's environment and climate, the scientists in the whole world and related personnel are looking for the solutions actively. In 2003, the low-carbon economy was mentioned in the government official document for the first time when the British government our energy future-creating a low carbon economy. The core of low-carbon economy is low energy consumption, low pollution and low emission; High effect, high efficiency and higher interest should be achieved in the development; the ultimate aim is to improve global environment and achieve the harmonious development between human and nature.

Since the word of low-carbon economic development model comes out, countries have worked on the theories and practice in succession. The related theories and social practice of low-carbon economy have been achieved the overall development and a kind of low-carbon economy system has been formed gradually. However, due to different economic model and pillar industries of each country and region, how to comprehensively measure the efficiency, achievement, existing problems and improvement of the low-carbon economic development becomes an important problem that need to be solved while low-carbon economy develop comprehensively. Especially in the city of Hebei Province, coal and steal are the pillar industry. While carrying out low-carbon economy comprehensively, how to achieve the comprehensive, long-term urban development is also an urgent problem to be solved. In the study, the city is taken as an example and the analytic hierarchy process is used to establish the economic evaluation system and evaluate the low-carbon economic status of the city in order to provide the theoretical basis for the low-carbon economic development.

\section{The basic principle of analytic hierarchy process}

The analytic hierarchy process (AHP) is a method of system analysis which uses qualitative analysis and quantitative analysis. The method makes the complicated problem become 
systematization, quantization and modeling. In other words, as for a complicated problem, firstly, it is decomposed into several components, and these components are decomposed further into more clear, specific and measurable elements named index. According to important degree and weight of each element in the same layer, the weight is used to connect each layer to form the multi-objective and multi-level statistical model, and the basic steps are as follows:

1) Establishing a multi-level hierarchical structure and forming a target three diagram. The analytic hierarchy model includes three layers, that is, top layer, middle layer and the lowest layer, as can be seen in the figure 1 . The top layer is target layer, that is, the general goal in the study of analytic hierarchal analysis; the middle layer which is called constrained layer includes several main factors affecting the general goal; the lowest layer which is called measures layer is the final measure and includes the measurable indicators.

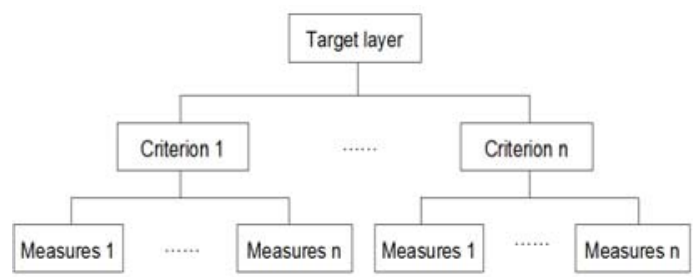

Fig 1 . The model structure of analytic hierarchy process

2) Constructing the comparison and judgment matrix and calculating weight value. The Saaty' s weighting method is used to compare the indexes and give the score firstly, and scoring criteria is shown in the figure1. Each index is compared to obtain the score, then the judgment matrix is established based on the score and the weight of each index is solved. The approximate weight of each index is:

$$
\overline{W_{i}}=\sqrt[m]{a_{i 1} a_{i 2 \cdots a_{i m}}}
$$

According to the formula, the approximate weight makes normalization process:

$$
W_{i}=\frac{\overline{W_{i}}}{\sum_{i=1}^{m} \bar{W}_{i}}
$$

Then each component is weight.

Tab 1. Scoring criteria of each layer in analytic hierarchy process

\begin{tabular}{|l|l|}
\hline Importance Scale $a_{i j}$ & Relative Important Extent \\
\hline 1 & equally important \\
\hline 3 & slightly important \\
\hline 5 & basic important \\
\hline 7 & really important \\
\hline 9 & absolutely important \\
\hline $2,4,6,8$ & intermediate value of adjacent degree \\
\hline & $\begin{array}{l}\text { If the ratio of importance between I and j is } a_{i j} \text {, then } \\
\text { Reciprocal }\end{array}$ \\
& the ratio of importance between $\mathrm{j}$ and ii is $a_{j i}=\frac{1}{a_{i j}}$. \\
\hline
\end{tabular}

3) Consistency Test

Consistency index

$$
\begin{gathered}
C I=\frac{\lambda_{\max }-m}{m-1} \\
\lambda_{\max }=\frac{1}{n} \sum_{i=1}^{m} \lambda_{i} / m \\
\lambda_{i}=\sum_{j=1}^{m} a_{i j W_{j} / W_{i}}
\end{gathered}
$$

Calculating the random index ratio

$$
C R=\frac{C I}{R I}
$$


RI expresses the average random index in the same order; according to different orders, its value is shown in table 2:

Tab 2. The value of average random index

\begin{tabular}{|l|l|l|l|l|l|l|l|l|l|}
\hline Order & 1 & 2 & 3 & 4 & 5 & 6 & 7 & 8 & 9 \\
\hline RI & 0.00 & 0.00 & 0.58 & 0.90 & 1.12 & 1.24 & 1.32 & 1.41 & 1.45 \\
\hline
\end{tabular}

If the CR value is less than 0.1, the consistency of judgment matrix is regarded as good.

4) Using the product method to calculate the combined weight. The combined weight is the coefficient is obtained by the weighed and multiplied indexes weight in different layers.

5) Calculating comprehensive score index. Suppose the measured value of ith evaluation index is $P_{i}$, the number of evaluation index is $\mathrm{m}$, and combined weight is ${ }^{C_{i}}$, then comprehensive score index is:

$G I=\sum_{j=1}^{m} C_{i} P_{i}$

According to the comprehensive score index, the judgment of the evaluation object can be realized.

\section{The construction of low-carbon economy evaluation system in the city}

In this study, the hierarchical structure of three layers is established through consulting the economic experts, referring to the related literature of the low-carbon economy evaluation and the actual situation.

Low-carbon economy evaluation system A

Consumption B1

Hard emissions per capita C1

Elasticity of energy consumption C2

Bus Ownership rate each thousand people C3

Private car ownership rate C4

Industry energy

Industrial waste gas total emission C5

Tertiary industry proportion C6

New energy proportion C7

High-tech industry proportion C8

CO2/GDP(Emission of CO2 per GDP) C9

SO2/GDP(Emission of SO2 per GDP) C10

Ecological environment

Forest coverage C11

Afforestation area C12

Per capita green area C13

Urban green coverage C14

Support

Environmental Protection proportion of the fiscal expenditure C15

Environmental protection agency staff number C16

Industrial Solid Waste comprehensive utilization rate C17

Number of waste gas treatment facilities C18

Using Saaty' s weight method to obtain the judgment matrix of evaluation system in each layer and its index weight, which is as follows: 
Tab 3. Judgment matrix and weight of evaluation system level 1 evaluation system

\begin{tabular}{|c|c|c|l|c|c|}
\hline Low-carbon Economy & Consumption & Industry Energy & Ecological Environment & Support & Weight Value \\
\hline Consumption & 1 & 0.25 & 0.333 & 0.5 & 0.093 \\
\hline Industry Energy & 4 & 1 & 2 & 3 & 0.446 \\
\hline Ecological Environment & 3 & 0.5 & 1 & 2 & 0.290 \\
\hline Support & 2 & 0.333 & 0.5 & 1 & 0.171 \\
\hline
\end{tabular}

Tab 4. judgment matrix and weight of evaluation system level 2 evaluation system (consumption)

\begin{tabular}{|l|l|l|l|l|l|}
\hline Consumption & C1 & C2 & C3 & C4 & Weight Value \\
\hline C1 & 1 & 2 & 3 & 4 & 0.446 \\
\hline C2 & 0.5 & 1 & 2 & 3 & 0.290 \\
\hline C3 & 0.333 & 0.5 & 1 & 2 & 0.171 \\
\hline C4 & 0.25 & 0.333 & 0.5 & 1 & 0.093 \\
\hline
\end{tabular}

Tab 5. Judgment matrix and weight of evaluation system level 2 evaluation system (Industry Energy)

\begin{tabular}{|l|l|l|l|l|l|l|l|}
\hline Industry Energy & C5 & C6 & C7 & C8 & C9 & C10 & Weight Value \\
\hline C5 & 1 & 3 & 4 & 4 & 0.333 & 5 & 0.261 \\
\hline C6 & 0.333 & 1 & 2 & 2 & 0.2 & 3 & 0.129 \\
\hline C7 & 0.25 & 0.5 & 1 & 1 & 0.167 & 2 & 0.074 \\
\hline C8 & 0.25 & 0.5 & 1 & 1 & 0.167 & 2 & 0.074 \\
\hline C9 & 3 & 5 & 6 & 6 & 1 & 7 & 0.422 \\
\hline C10 & 0.2 & 0.333 & 0.5 & 0.5 & 0.143 & 1 & 0.040 \\
\hline
\end{tabular}

Tab 6. Judgment matrix and weight of evaluation system level 2 evaluation system (Ecological Environment)

\begin{tabular}{|l|l|l|l|l|l|}
\hline Ecological Environment & C11 & C12 & C13 & C14 & Weight Value \\
\hline C11 & 1 & 5 & 3 & 7 & 0.507 \\
\hline C12 & 0.2 & 1 & 0.333 & 3 & 0.144 \\
\hline C13 & 0.333 & 3 & 1 & 5 & 0.296 \\
\hline C14 & 0.143 & 0.333 & 0.2 & 1 & 0.053 \\
\hline
\end{tabular}

Tab 7. Judgment matrix and weight of evaluation system level 2 evaluation syste (Support)

\begin{tabular}{|c|c|c|c|c|c|c|c|}
\hline rt & C15 & C16 & C17 & C18 & C19 & C20 & Weight Value \\
\hline C15 & 1 & 4 & 5 & 3 & 2 & 4 & 0.350 \\
\hline C16 & 0.25 & 1 & 2 & 0.5 & 0.333 & 1 & 0.094 \\
\hline C17 & 0.2 & 0.5 & 1 & 0.333 & 0.25 & 0.5 & 0.051 \\
\hline C18 & 0.333 & 2 & 3 & 1 & 0.5 & 2 & 0.163 \\
\hline C19 & 0.5 & 3 & 4 & 2 & 1 & 3 & 0.249 \\
\hline C20 & 0.25 & 1 & 2 & 0.5 & 0.333 & 1 & 0.094 \\
\hline
\end{tabular}

Formula three, formula four, formula five and formula six, which are used to calculate the CR value of each matrix, the result is shown in table 8.

Tab 8. Consistency Checking Result

\begin{tabular}{|l|l|l|}
\hline Matrix & CR & Consistency Result \\
\hline Level 1 Matrix A & 0.035 & Satisfactory \\
\hline Level 2 Matrix B1 & 0.016 & Satisfactory \\
\hline Level 2 Matrix B2 & 0.021 & Satisfactory \\
\hline Level 2 Matrix B3 & 0.037 & Satisfactory \\
\hline Level 2 Matrix B4 & 0.015 & Satisfactory \\
\hline
\end{tabular}

From the table 8, CR value of each judgment matrix is less than 0.05, which expresses each matrix has consistency of satisfactory. Furthermore, the product method is used to calculate the combination weight value of the lowest level index, as is shown in table 9. 
Tab 9. The combination weight value of the lowest value index

\begin{tabular}{|c|c|c|c|c|}
\hline A Level & $\begin{array}{l}\text { B Level Weigh } \\
\text { Index }\end{array}$ & C Level Weight Index & $\begin{array}{r}\text { Combination } \\
\text { Weight }\left(\omega_{i}\right) \\
\end{array}$ & Index Direction \\
\hline \multirow{20}{*}{$\begin{array}{l}\text { Low- } \\
\text { Carbon } \\
\text { Economy } \\
\text { Evaluation }\end{array}$} & \multirow{4}{*}{$\begin{array}{l}\text { Consumption } \\
\text { B1 }(0.093)\end{array}$} & C1 (0.446) & 0.041 & negative \\
\hline & & C2 $(0.290)$ & 0.027 & negative \\
\hline & & C3 $(0.171)$ & 0.016 & positive \\
\hline & & C4 $(0.093)$ & 0.009 & negative \\
\hline & \multirow{6}{*}{$\begin{array}{l}\text { Industry } \\
\text { Energy } \\
(0.446)\end{array}$} & C5 $(0.261)$ & 0.116 & negative \\
\hline & & C6 (0.129) & 0.058 & positive \\
\hline & & C7 $(0.074)$ & 0.033 & positive \\
\hline & & C8 $(0.074)$ & 0.033 & positive \\
\hline & & C9 $(0.422)$ & 0.188 & negative \\
\hline & & C10 $(0.040)$ & 0.018 & negative \\
\hline & \multirow{4}{*}{$\begin{array}{l}\text { Ecological } \\
\text { Environment } \\
(0.290)\end{array}$} & C11 $(0.507)$ & 0.147 & positive \\
\hline & & C12 $(0.144)$ & 0.042 & positive \\
\hline & & C13 $(0.296)$ & 0.086 & positive \\
\hline & & C14 $(0.053)$ & 0.015 & positive \\
\hline & \multirow{6}{*}{$\begin{array}{l}\text { Support } \\
(0.171)\end{array}$} & C15 $(0.350)$ & 0.060 & positive \\
\hline & & C16 (0.094) & 0.016 & positive \\
\hline & & C17 $(0.051)$ & 0.009 & positive \\
\hline & & C18 $(0.163)$ & 0.028 & positive \\
\hline & & C19 $(0.249)$ & 0.043 & positive \\
\hline & & C20 $(0.094)$ & 0.016 & positive \\
\hline
\end{tabular}

From the above analysis result, the weight of energy industry is the biggest in the four level 2 evaluation indexes. The industry energy, the proportion of the emission of CO2 of per unit GDP is the biggest in the evaluation index. At present, our country is energy country. The rapid economic development mainly relies on the consumption of energy and the emission of CO2 after the energy consumption, which reminds us that low-carbon economy cannot develop at the cost of energy consumption and new energy industry, high-tech industry and the tertiary industry should develop rapidly to promote the total economic growth.

Among the above twenty third grade indexes, due to the meaning and unit of each index are different, the standardized processing is carried out. In this study, the standardized method is $c_{i j}{ }^{\prime}=\frac{c_{i j}}{\max c_{i j}}$ each index has not unit. However, among the third degree indexes, some are positive indexes and some are negative indexes. In order to keep the indexes in the same direction, negative indexes are processed and the processing method is $c{ }^{\prime \prime}{ }^{\prime \prime}=1-c_{i j}{ }^{\prime}$; all indexes become the positive indexes after treatment and LCI is calculated by using the linear weighting method; the calculation method

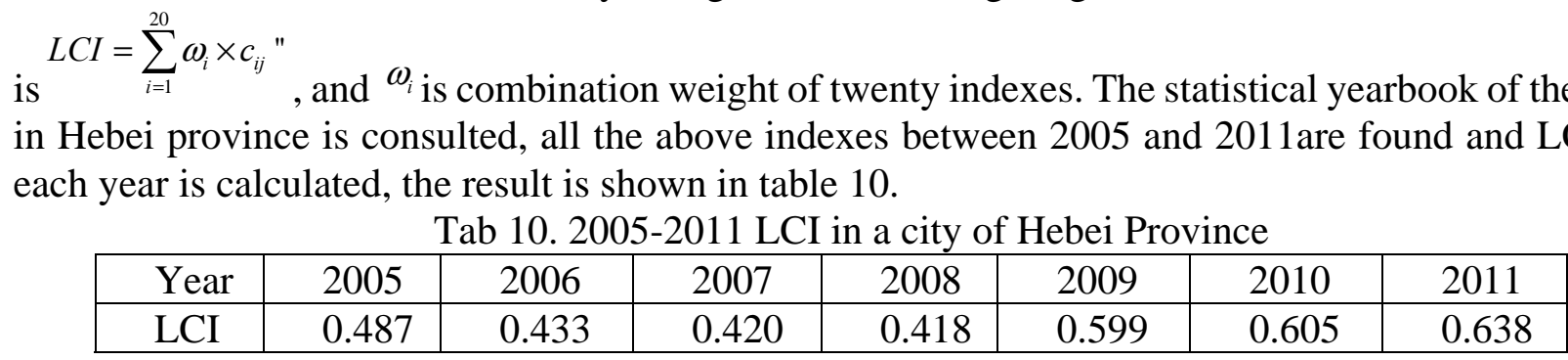

As can be seen from table 10, the development level of low-carbon economy improves steadily in a city of Hebei Province. But there is a sudden fall in the year 2006, 2007 and 2008. Maybe the reason is real estate industry is prosperous in those three years. The demand of steal and cement in the whole society is large, but those are the polar industry of the city. The stimulation of the market and impel of economy result in the fall of low-carbon economy development level. 


\section{Conclusions}

In the study, the analytic hierarchy process is used to establish the low-carbon economy evaluation system and LCI is combined to compare the low-carbon economy development level between 2005 and 2011 in a city of Hebei province. The problem is found and proposal is put forward, which provides guiding value for low-carbon economic development in the other cities of Hebei province and even in the whole country. However, there is shortage in the study. When establishing the evaluation system, the selected indexes are measurable and statistical indexes; but the indexes that the government did not count are not introduced into evaluation system, which may affect evaluation system; in the future research, all indexes should be selected to establish the low-carbon economy evaluation system of all indexes.

\section{References}

[1] Li Xiaoyan . An Exploration of Low-carbon Economy of Provinces Based on Fuzzy Analytic Hierarchy Process (FAHP) [J]. East China Economic Management, 2010, (2).

[2] Kang Ying, Xue Lianqing. Application of Improved Fuzzy AHP Method in Comprehensive Water Price Determination[J]. Water Saving Irrigation, 2008, (1).

[3] Sustainable Development Strategy Research Team of Chinese Academy of Sciences[M]. Bei Jing: Publishing House of Chinese Social Sciences, 2009.

[4] Tao Lianghu. The New Way of Hubei Economic Development and Transcendence[J]. Journal of Hubei Administration Institute, 2010, (1).

[6] Xu Ruie. The Research Review of Developing Chinese Low-carbon Economic Policy[J]. Review of Economic Research, 2009, (66).

[6] Niu Fengjun, Liu Wencui. On Constructing Evaluating System of Low-carbon Economy in Xinjiang[J]. Journal of Xinjiang University of Finance \& Economics,2010(4).

[7] Zhou Fuhua, Chen Xiong. The Preliminary of Low-carbon Economy at Home and Abroad[J]. Contemporary Economics, 2011(9).

[8] Wang Shuguang, Diao XiaoJUN, Mu Nan. The Study on Constructing Low-carbon Economic Supervision System by Using Environmental Monitoring Experience. Environmental Pollution \& Control, 2011(10).

[9] Li Yunyan. The Evaluation Method and Implementation Approach of Low-carbon City[J]. Macroeconomic Management, 20ll(3): 5l-53.

[10] Ren Fubing, Wu Qingfang, Guo Qiang. The Construction of Low-carbon Society Evaluation Index System. Jianghuai Tribune, 2010(11): 122-126.

[11] Pan Jiahua, Zhuang Guiyang, Zhengyan. Clarification of the Concept of Low-Carbon Economy and Analysis of its Core Elements[J]. International Economic Review, 2010(4): 88-101.

[12] Fu Jiafeng, Zhuang Guiyang, Gao Qingxian. Conceptual Identification and Evaluation Index System for Low Carbon Economy[J]. Population, Resources and Environment, 2010(8): 38-43.

[13] Tang Xiaofei, Lu Chunxia, An Kai. Development Levels of Low-Carbon Economy at Provincial Scales in China[J]. Resources Science, 201l(4): 612-619.

[14] Fu Jiafeng, Zheng Linchang, Cheng Xiaoling. China’s Low-Carbon Economic Development: An Inter-Provincial and International Comparison[J].Resources Science,2011(4): 664-674.

[15] Wang Binbin. The Study on the Construction and Experience of Low-carbon Economy Evaluation System[J]. Journal of Dongbei University of Finance and Economics, 2010(6): 46-51.

[16] Zhang quan, Ye Xingping, Chen Guowei. Low-Carbon Urban Planning: A New Vision[J]. City Planning Review, 2010(2): 13-18.

[17] Pan Jiahua, Zheng Yan, Zhuang Guiyang. Explore and analyze the Concept of Low-Carbon Economy Methodology[A]. Low-carbon Development(Volume 1)[M].Bei Jing: China Environmental Science Press, 2009: 200-229. 
[18] Wang Geng, Wang Minsheng. The Modern Mathematic Modeling Method [M]. Bei Jing: Science Press, 2008: 215-222. 